\title{
Imaginário Amazônico e Territorialidade Festiva: o Divino na Festa do Sairé de Alter do Chão (Pará/PA, Brasil)
}

\author{
Amazonian imaginary and festive territoriality: Divine at the Sairé Party in \\ Alter do Chão (Pará / PA, Brazil)
}

\author{
Maria Augusta Freitas Costa Canal (CANAL, M. A. F. C.) ${ }^{*}$
}

\begin{abstract}
RESUMO - A festa se revela nos espaços turísticos como evento arrolado a um calendário, sendo sua produção cultural, com as dimensões do imaginário, vinculada apenas como um atrativo na lógica da demanda e da oferta. O objetivo central desse texto consistiu em identificar e analisar a relação entre a construção da territorialidade festiva no Sairé e o imaginário amazônico sobre o Divino, num espaço de envolvimentos culturais vinculados ao turismo. A metodologia usada foi de caráter qualitativo, baseada em análise bibliográfica e documental, observação dirigida e entrevista semiestruturada com os organizadores da festa do Sairé em Alter do Chão (Pará, Brasil), em trabalhos de campo realizados entre 2012 e 2016. O resultado da pesquisa indicou um forte atrelamento entre o imaginário amazônico e a festa do Sairé como veículo de produção de subjetividades coletivas e a objetivação de projetos que mediam o fazer o Sairé como territorialidade festiva. Sendo sua materialidade e imaterialidade demonstração de coesão social aos grupos que organizam o fazer festivo e a expressão cultural diferenciada sobre/com o Divino.
\end{abstract}

Palavras-chave: Turismo; Territorialidade; Imaginário; Festas; Amazônia.

ABSTRACT - The party is revealed in tourist spaces as an event within a calendar, being a cultural production, with the dimensions of the imaginary and it is only linked as an attraction in the logic of demand and offer. The central objective of this paper was to identify and analyze the relationship between the construction of the festive territoriality in Sairé and the Amazonian imaginary about the Divine, in a space of cultural entanglements linked to the tourism. The methodology used was qualitative, based on bibliographical and documental analysis, directed observation and semistructured interviews with the organizers of Sairé Party in Alter do Chão (Pará, Brazil), in fieldwork conducted between 2012 and 2016. The result of the research indicated a strong link between the Amazonian imaginary and the Sairé Party as a vehicle for the production of collective subjectivities and the objectification of projects that mediate the the Sairé as a festive territoriality. Being its materiality and immateriality demonstration of social cohesion to the groups that organize the festivity and the differentiated cultural expression on/with the Divine.

Key words: Tourism; Territoriality; Imaginary; Parties; Amazon.

\footnotetext{
* Formação: Graduação em Licenciatura e Bacharelado em Geografia pela Universidade Federal do Pará (UFPA). Mestrado em Geografia pela UFPA. Doutorado em Geografia pela FCT/UNESP-Presidente Prudente. Atividade profissional: Professora Adjunta da Faculdade de Turismo do Instituto de Ciências Sociais Aplicadas da UFPA. Endereço físico para correspondência: Rua Augusto Corrêa, 01 - Guamá. CEP 66075-110 - Belém - Pará - Brasil. E-mail: augustageotur@gmail.com
} 


\section{INTRODUÇÃO}

As festas representam uma esfera do patrimônio cultural humano que expressa relevância na sociedade da fluidez e da mobilidade da qual os seres humanos são contemporâneos (MENESES, 2006), isso porque, como já indicava Durkheim (1989), as festas reúnem ritos sociais marcados pelo prazer, pela transgressão e pela reanimação "para o labor cotidiano". Tais marcas coadunam com a prática que é uma das que mais tem mobilizado e dado fluidez às massas humanas: o turismo, atividade de lazer mediada pela viagem que induz novas formas de socialização e sociabilidade (URRY, 1996; ARAÚJO, 2001; SANTANA, 2009), cujos "lugares são escolhidos pela motivação da expectativa dos devaneios e da fantasia em relação a prazeres intensos" (URRY, 1996, p. 11). Pensa-se, a partir de interações teóricas entre Guattari (1992), Dematteis e Ferlaino (2003) e Raffestin $(1985,1993)$, que a territorialidade representa o processo pelo qual os grupos humanos elaboram e/ou aderem a projetos de territorialização. Julga-se ser esse aspecto relevante ao entendimento do sentido ao acionamento de elementos plasmáticos de intencionalidade e ação objetiva a projetos de espacialidades em condição de se instanciar como atores/ações sociais em alteridades singulares de territorializações materiais/imateriais existencializantes.

Nesse contexto, procurou-se ressaltar a construção de uma territorialidade festiva que dá sentido e ação objetivada ao/de mundo amazônico a partir/com o Sairé como mover contínuo da construção de subjetividades coletivas que prospectam sentido à constituição de atores sociais. Dessa perspectiva, o "festejar" ou "o fazer a festa" configuram-se enquanto campo social de significações e representações (AMARAL, 1998) que, ao serem acionadas para autoafirmação de identificações por um grupo social, passam a compor a esfera imaterial do patrimônio cultural desse grupo (PRATS, 1998; MENESES, 2006; BERTONCELLO, 2010). Para Paes (2010, p. 13), o patrimônio imaterial corresponde a articulações mais atuais da patrimonialização de bens culturais que se orientam pelas "práticas, representações, expressões, conhecimentos e técnicas da cultura imaterial". Como assestam Wagner (1981) e Sidekum (2003), a cultura se fundamenta em sujeitos sociais concretos que coletiva e rotineiramente criam variáveis de identificação cultural, nesse viés, o patrimônio imaterial é "síntese de elementos inovados, transportados, assimilados num processo histórico" (WAGNER, 1981, p. 293). 
Desse modo, conforme Meneses (2006), o uso turístico do patrimônio deve assimilar de maneira radical os processos históricos, ponderando as bases cotidianas que lhe dão forma e lhe problematizam e que permitam a sua "contextualização instigante". Conforme Nistsche e Bahl (2016), o envolvimento entre aqueles que se deslocam pela/na viagem turística, e aqueles que recebem os viajantes, propicia o deslocamento de culturas provenientes de construções socais e subjetividades coletivas, tornando mais vulneráveis às culturas dos grupos sociais receptores e seus patrimônios materiais e imateriais. Neste artigo, objetivou-se analisar a relação entre a construção da territorialidade festiva pelo/no Sairé e o imaginário amazônico sobre o Divino, num espaço de envolvimentos culturais vinculados ao turismo. Os resultados aqui discorridos procedem de um extenso levantamento bibliográfico e documental, assim como de trabalhos de campo, realizados entre os anos de 2012 e $2016^{1}$. Nesse ínterim, se efetuou observação dirigida e entrevistas semiestruturadas (LAKATOS, MARCONI, 1993) com os organizadores do fazer festivo do Sairé. Daí decorreram notas de campo e relatos derivados de 34 entrevistas realizadas de forma aleatória em Alter do Chão, em setembro de 2012, outubro de 2013 e janeiro de 2014.

A festa do Sairé é realizada a cada mês de setembro na Vila de Alter do Chão ${ }^{2}$ que corresponde à sede do distrito administrativo Eixo Forte e distante aproximadamente três quilômetros da sede municipal de Santarém no oeste do estado amazônico do Pará, conforme se pode ver no mapa 1 exposto a seguir. Essa festa se delineia simbolicamente entre as Folias e as Ladainhas e, as Danças; concretamente realizadas nas adjacências de um barracão de palha, erguido pelos sujeitos locais envolvidos com a festa e nas apresentações denominadas pelos organizadores de folclóricas, especialmente no Lago dos Botos. A Praça do Sairé é o espaço mítico/sagrado/profano e sintetiza as estratégias de mobilização cultural que constroem o imaginário amazônico da Festa do Sairé em tempos turísticos (COSTA, 2012). Esse imaginário é substrato de arranjos e negociações nas diversas escalas geográficas, desde

\footnotetext{
${ }^{1}$ Nesse período acompanhamos a efetuação da Festa do Sairé por ocasião da produção da tese de doutoramento.

2 A localidade de Alter do Chão recebe fluxos turísticos desde a década de 1970 (PEREIRA, 2007), fluxos esses impulsionados pela construção da rodovia Everaldo Martins e pelas vantagens locacionais de seu território que funciona como ponto difusor desses fluxos. Os fluxos são originários de diversas partes da região amazônica, de outras partes do Brasil (principalmente Rio de Janeiro e São Paulo) e de diversas partes do mundo (especialmente da Itália, Inglaterra, Suíça e Alemanha), que aportam em Belém ou em Manaus e se direcionam para Alter do Chão.
} 
a local, passando pela regional com conexões com a festival de Parintins, à escala nacional e internacional com o imaginário turístico convocante, seja por meio de políticas públicas ou de indução de fluxos turísticos.

MAPA 1

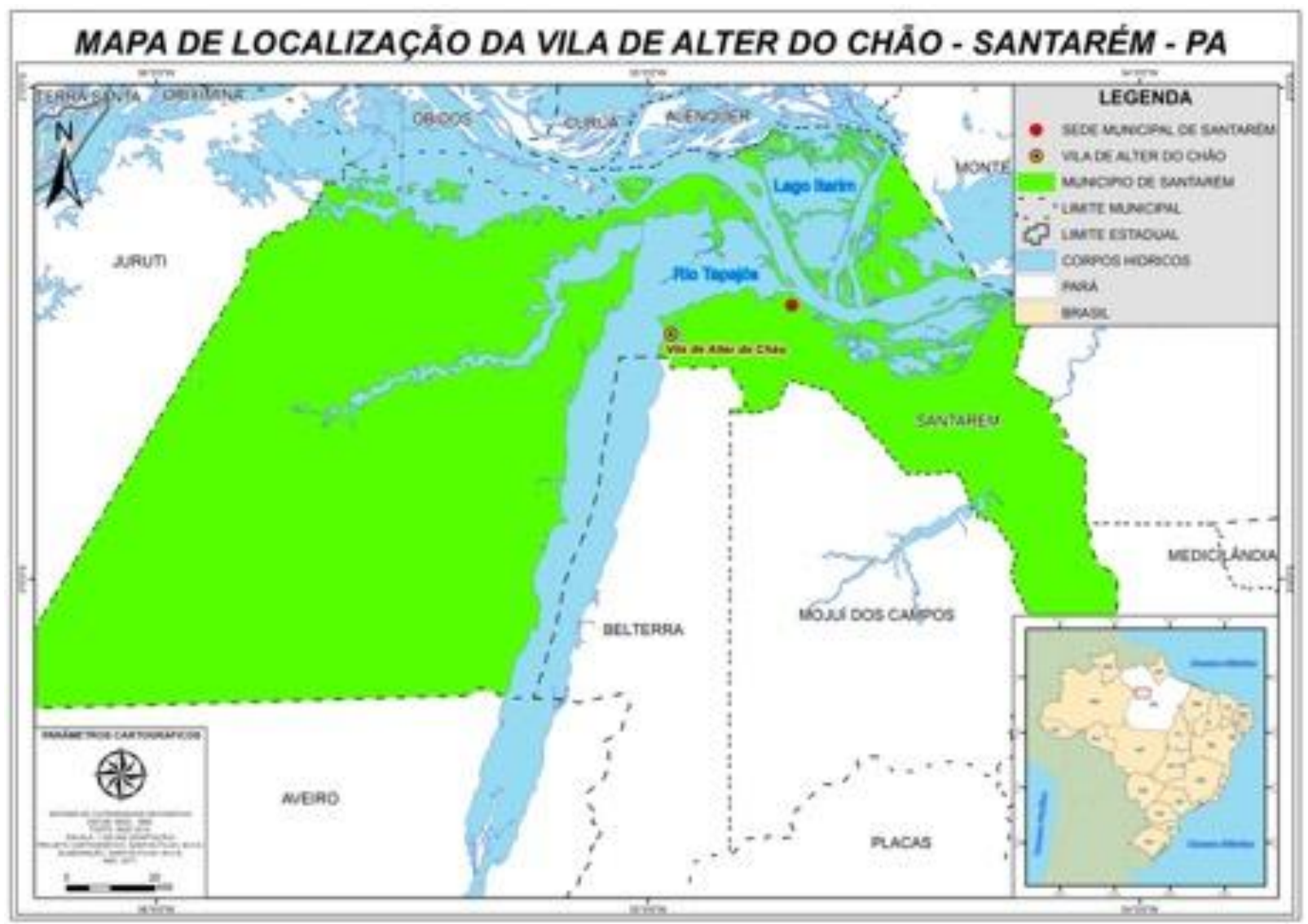

FONTE: Elaborado a partir de pontos referenciados em Trabalho de Campo, Alter do Chão, Jan. 2014.

Conforme se constatou através de Rodrigues (1890), Pereira (1989) e Daniel (2004), a festa do Sairé se realizava em toda a bacia do rio Amazonas da segunda metade do século XVII até a primeira metade do século XX, quando a partir da ingerência de católica de romanização ${ }^{3}$ deixou de ser estimulada e realizada na Amazônia. Isso se evidencia nas análises sobre sua estrutura ritualística fundamentalmente inspirada na "autenticidade de um fato histórico - o culto ao Divino Espírito Santo, estabelecido então em Portugal desde o século XVI” (PEREIRA, 1989, p. 28). De acordo com as notas descritivas geradas das observações dirigidas e com os

\footnotetext{
${ }^{3}$ Segundo Maués (1995) e Lustosa (1992), o processo de romanização delineou a centralização do poder do vaticano romano e da autoridade papal sobre a religião católica tendo suas diretrizes dimensionadas pela busca de: autonomia político-administrativa e autonomia político-religiosa.
} 
relatos das entrevistas realizados com os organizadores da festa do Sairé, a recrudescência na década de 1970 dessa festa na localidade deu-se por empenho de moradores locais que buscavam fortalecer os fazeres festivos locais ante um contexto de intensa interação com fluxos turísticos regionais, nacionais e internacionais (PEREIRA, 2007). Nesse contexto, o Divino aparece como um arquétipo dentro da estrutura ritualística da Festa do Sairé tendo o Semicírculo do Sairé como uma idiossincrasia e a materialidade simbólica expressa pela Coroa do Divino Espírito Santo como o elo comum incutidos em sua estruturação.

\section{A FESTA DO SAIRÉ E A CRIAÇÃO IMAGINATIVA DO DIVINO AMAZÔNICO}

A festa do Sairé de Alter do Chão abriga as dimensões do Divino em que a Coroa "é o próprio Espírito Santo" (INFORMAÇÃO VERBAL) ${ }^{4}$; as Três (3) cruzes sustentadas no estandarte Sairé "representam o Pai, o Filho $e$ o Espirito Santo"(INFORMAÇÃO VERBAL) ${ }^{5}$; e pelas Bandeiras - uma Vermelha e outra Branca sobre as quais estão desenhadas a Poma do Espírito Santo ${ }^{6}$. Em torno da estruturação do Divino e de suas materialidades simbólicas, no interior da territorialidade festiva do Sairé cerimônias envoltas por Folias. Mas, partindo de argumentações encontradas em Maués (1995, p. 479), considera-se que essa dimensão do divino não pode ser tomada sem as peculiaridades amazônicas vinculadas aos ciclos de festa de santos em interface a pajelança que permitem "entender melhor a sociedade amazônica, sobretudo aqueles aspectos mais tradicionais". Tais proposições apresentam importância para revelar as argumentações culturais que dão suporte ao sistema simbólico embutido no fazer o Sairé, dado que o tempo presente do festejar o Sairé é imbricado de práticas pretéritas as quais não se sustentam no presente.

Entende-se, a partir de Castoriadis (1991), que a instituição da sociedade configura-se pelos sistemas simbólicos criados pelo imaginário social que opera a

\footnotetext{
${ }^{4}$ Organizadora da Festa, 63 anos de idade, entrevista realizada em Alter do Chão, Set. 2012.

${ }^{5}$ Organizadora da Festa, 79 anos de idade, entrevista realizada em Alter do Chão, Out. 2013.

${ }^{6}$ Informação constatada nos relatos das entrevistas realizadas nos trabalhos de campo efetuados entre Out. 2013 e Jan. de 2014 em Alter do Chão.
} 
realidade e a racionalidade, inscreve-se a festa do Sairé e seu sistema simbólico como produtos da realidade e da racionalidade imaginativa do colonizador português e do sistema religioso de elementos do catolicismo ibérico, mesclado a um catolicismo popular e a pajelanças praticados na Amazônia (MAUÉS,1995). Essa festa tem raízes no período colonial quando em aldeias, vilas e lugarejos amazônicos se utilizava um semicírculo contendo três (3) cruzes representando a Santíssima Trindade e denominado Sairé para acompanhar as procissões de Santos Católicos. Também eram utilizados ritos e símbolos da festa do Divino Espírito Santo como mordomos e juízes, ladainhas e folias, e as "danças de índios" realizadas em círculo em especial do grupo Borari (GALVÃO, 1976; PEREIRA, 1989; FERREIRA, 2008). Reside nesse imaginário da Festa do Sairé todo um construto festivo amazônico, cujo resíduo ou rugosidade espacial (SANTOS, 1999) se assenta em Alter do Chão, a saber: nos elementos imaginativos da natureza e na integração sacro/santa desses com o universo mítico e/ou religioso católico, que remete a uma criação poética nas composições musicais e narrativas sobre a Festa do Sairé como encontrados nos seguintes trechos musicais: "Em Alter do Chão/ Não se sente dor/ Tem um povo pobre/ Mas acolhedor/ Por Deus foi criada a tua beleza/ Suas lindas praias/ São da natureza" (FERREIRA, 2008, p. 89) e “Lá vem a Estrela D’Alva/ Trazendo a Aurora Divina/ Lá vem a pomba voando/ Saindo da Matriz/ Vem dizendo viva, viva"(INFORMAÇÃO VERBAL) ${ }^{7}$.

Não se aprofundará aqui a discussão poética das músicas e narrativas, mas sim do imaginário instaurador da sociedade amazônica que modela a construção imaginativa do Sairé. Esse imaginário sacro/santo vinculado ao natural incide sobre os rearranjos ou ressignificações dentro do conjunto da festa, como no caso da composição das Danças e inserção do espetáculo dos Botos e as dimensões simbólicas/imaginativas que, tomando como referência Castoriadis (1991), lhe legítima como meio ritualístico que sacramenta a instituição imaginativa e sistemas simbólicos da sociedade amazônica. A ordem ritualística e simbólica dentro do festejar o Sairé cria uma realidade que coaduna com o imaginário festivo amazônico os quais possuem uma intrínseca relação entre culto e regozijo (AMARAL, 1998), componente da natureza das festas religiosas regionais, em especial nas festas paraenses, em que as expressões de cerimonia e de festividade estão fortemente atreladas. Em se tratando da Festa do Sairé, Pereira é enfático ao afirmar que

\footnotetext{
${ }^{7}$ Elocução extraída de gravação realizada durante a procissão para elevação dos Mastros, derivada dos trabalhos de campo efetuados em Set. de 2012.
} 
desde suas primeiras práticas "não se admitiam, então como hoje, festas religiosas sem bebidas e comidas" (BATES, 1962, p. 84).

Nessa perspectiva, institui-se uma realidade festiva que não é uma sombra distorcida do real, apesar de nele ter referências, as imagens daí decorrentes legitimamse no ritual que é ação valorizada por uma ordem simbólica (CASTORIADIS, 1991). Argumentando sobre a representação simbólica, Bourdieu (2003) alerta para o cuidado necessário com as representações simbólicas, já que, essas não podem ser consideradas um falseamento da realidade. Resguardadas as concepções, escolas e métodos entre os dois autores, ambos auxiliam no entendimento de como as emoções criam racionalidades indissociáveis das bases sociais de uma dada realidade. Segundo diz Wagner (1981, 2011), esse é o caráter da dependência que tradição tem na inovação, pois seu devir necessita da dialética sim síntese final entre convenção-memória (transmissão) e invenção-improvisação (inovação) que conforma um espaço de infinitas combinações simbólicas circunscrita em um "contexto" cujo significado deriva da relação e não especifica e restritamente dos signos/significantes. A instância de criação/invenção cultural na Festa do Sairé expressa a mediação entre mundo interior e exterior em Alter do Chão, e isso fica evidente quando se analisa o uso histórico do termo "Sairé" como elocução designativa à celebração festiva, à materialidade do signo Sairé e à saudação para adentrar as rodas de danças.

Assim, de acordo com Pereira (1989), Santiago (1996) e Ferreira (2008), o termo Sairé é atribuído ao ritual festivo como um todo, ao semicírculo da Santíssima Trindade e, à saudação que em nheengatu indica "salve tu”, expressão que era usada para receber quem adentrava ao círculo das danças. $\mathrm{O}$ que indica conforme a função do imaginário derivada da visão de Castoriadis (1991, p. 93): “a criação incessante e essencialmente indeterminada de figuras, formas, imagens, a partir das quais somente é possível falar de alguma coisa". Dessas três designações, citadas anteriormente, sobre o Sairé, as duas primeiras ainda são mantidas nas práticas festivas locais e refletem o papel da igreja católica como indutora das festas inspiradas no Espirito Santo (CASCUDO, 1988). A designação das cerimonias de procissão, ladainha e folias criadas em arquétipo festivo e a representação simbólica material da festa do Sairé dada pelo semicírculo recoberto por fitas coloridas e contendo quatro cruzes que representam a Trindade Divina unificada, como é possível ver na figura 1 exposta na próxima página. Segundo Rodrigues (1890) 
e Daniel (2004), o uso do Semicírculo Sairé nas rodas de danças indígenas e nas cerimonias festivas de Santos Católicos teria uma "suposta" atribuição aos padres jesuítas na Missão Tapajós (RODRIGUES, 1890) quando tinha como marca alegórica o algodão e pedaços de espelhinhos utilizados para aproximar os "selvagens" da igreja católica que, a princípio, eram carregados por meninos e meninas durante a "procissão bailada" (DANIEL, 2004; FERREIRA, 2008) e, posteriormente, de acordo com Pereira (1989), teriam sido substituídos gradualmente por "velhas" ou as "velhas do Sairé" (SMITH, 1879).

FIGURA 1 - O SAIRÉ ENQUANTO SIGNO MATERIAL EM SEMICÍRCULO E DIMENSÃO DE PROCISSÃO

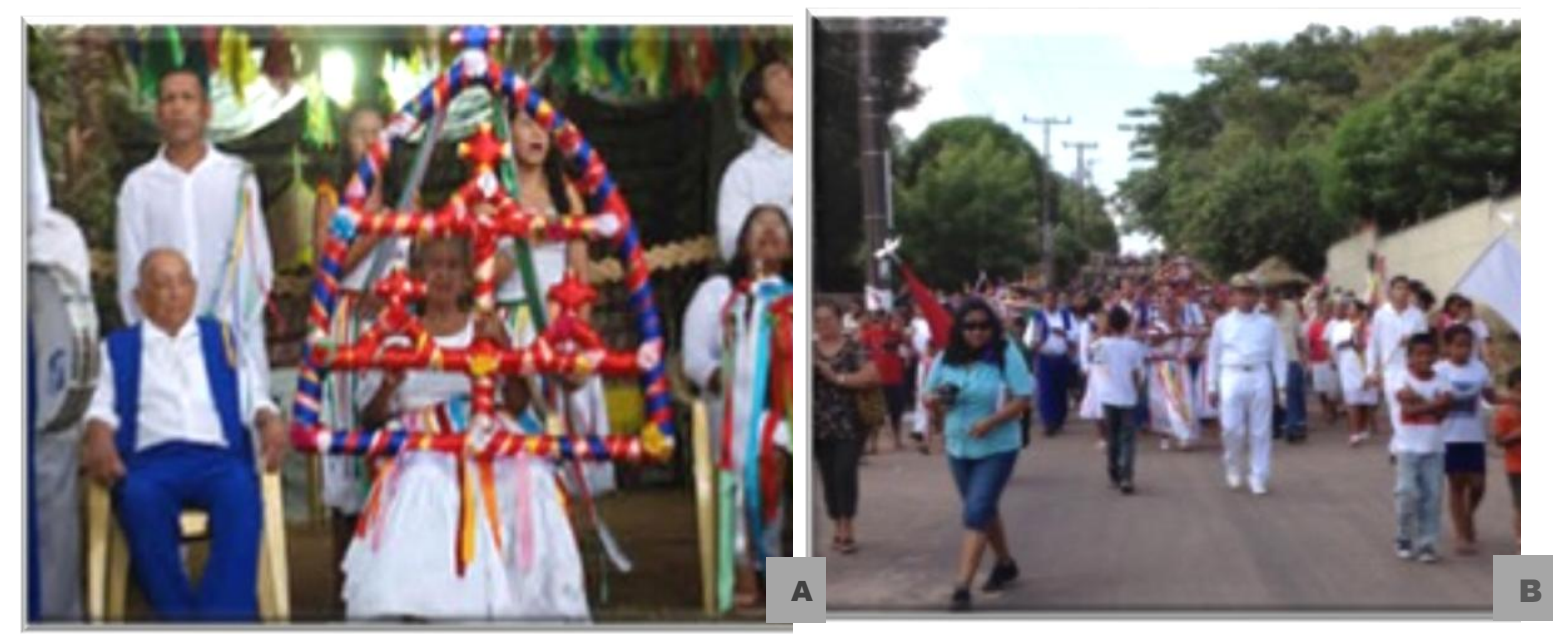

A - SEMICÍRCULO DO SAIRÉ NO COLO DA SARAIPORA E COROA DO DIVINO NO COLO DA JUÍZA DA FESTA NA CERIMÔNIA DE ABERTURA DA FESTA; B - PERSPECTIVA DE UMA DAS PROCISSÕES DAS CELEBRAÇÕES DOS MASTROS FESTIVOS NO SAIRÉ.

FONTES: a: <http://notapajos.globo.com>, acessado em: 16 de out. de2013. b: Arquivo Particular, Set. 2012.

Na figura 1, o signo material em Semicírculo Sairé é apresentado no colo de uma anciã local e como centralidade tanto na cerimônia de abertura da festa quanto em uma das procissões da festa ${ }^{8}$. Três aspectos apresentados nessa figura merecem destaque pela importância constitutiva ao imaginário que persiste atualmente na festa do Sairé como hegemonia de um "Divino" baseado: a) na trindade do catolicismo impregnado nas cruzes no interior do semicírculo apresentado na foto $\boldsymbol{a}$; b) nas devoções do cristianismo baseado no Espírito Santo que se exprime pela coroa recoberta com fitas

\footnotetext{
${ }^{8}$ Essas caraterísticas foram proeminentes tanto nas notas descritivas quanto nos relatos das entrevistas provenientes dos trabalhos de campos realizados entre ago./set de 2011; set./out. de 2012 e; de set. de 2013 a dez. 2014.
} 
apresentada no canto direito da foto $\boldsymbol{a}$ sobre as mãos de uma senhora e; c) no reordenamento do sentido e direção das expressões de esfera circular para esfera linear das procissões como se verifica na foto $\boldsymbol{b}$, onde é possível, também, observar nos cantos a presença de duas bandeiras que fazem alusão ao divino e ao centro um sujeito vestido de capitão abrindo a procissão. Assim, se por um lado, detectou-se no interior da festa uma dimensão na trindade divina veiculada às festas do catolicismo e o coroamento do Espirito Santo das festividades de irmandades cristões ${ }^{9}$, por outro lado, se encontram elementos vinculados à expressão do feminino e ao não coroamento ou destituição de um Império do Divino como visto em festividades do Divino Espírito Santo veiculadas por expressões do catolicismo e cristianismo.

Atrelado a isso, detectou-se nessas práticas festivas no Sairé a composição de um corpo de organizadores e condutores com proeminência distintiva entre sexo/gênero entre: Mordomos e Mordomas, Juiz e Juíza, Procurador e Procuradora etc., bem como, dos mastros festivos, elemento recorrente das festas de Santos brasileiras (SANTIAGO, 1996; AMARAL 1998), mas que na festa do Sairé de Alter do Chão se apresentou com o diferencial plural: dois mastros, um do Juiz para os homens e outro da Juíza para as mulheres. E, o caráter das cerimonias e arquétipos designados às danças como uma representação simbólica da festa do Sairé tanto "o caráter social da dança do Sahiré (como procissão) e o das diversas danças (lundu, baião etc.)" (PEREIRA, 1989, p. 49). A mobilidade impressa nas danças e suas tipologias na festa do Sairé apresenta, assim como, o calendário festivo, uma transitoriedade que se ordena no movimento das composições sócio-espaciais e que durante a realização da pesquisa apresentou-se, incisivamente, enredadas à "Disputa dos Botos". Como aponta Ferreira (2008), a inserção da "Disputa dos Botos" no final da década 1990 como componente centralizador das "Danças" apresentadas durante a realização da Festa do Sairé foi engendrada em uma ampla discussão sobre o papel das "lendas do boto" na região e sua representação lúdico-simbólica de religiosa entre o bem e o mal tendo o boto animal o Boto Tucuxi (Sotália Brasiliensis) e Boto Cor de Rosa (Inia geoffrensis) em interface ao potencial sexual e sedutor de sua metamorfose em homem e à proteção das águas e do pescador, podendo tanto provocar naufrágios, salvar náufragos, atrair e carregar sujeitos ao fundo de corpos hídricos.

\footnotetext{
${ }^{9}$ Para um maior detalhamento dessas tipologias veja-se Lopes (2004).
} 
Nesse sentido, dois aspectos se apresentam como enfáticos à composição do Divino no imaginário amazônico inerente a festa do Sairé: o feminino e a água (o líquido/fluído). Como argumenta Bachelard (2002), a negociação revela o caráter de construto social manifesto pelo imaginário e pela imaginação, os quais incisivamente referenciam a natureza e o espaço. Sendo segundo o autor, os elementos simbólicos vinculados à água revelam-se como "imaginação material" de elemento mais feminino. O feminino, segundo Galvão (1976) e Maués (1995), é o que melhor constitui a base imaginária amazônica que institucionaliza o sagrado/mítico nas formas e leis divinas da natureza seja respectivamente, conforme os autores, através de seres visagentos ou encantados que correspondem a construções místicas duais entre humanos e nãohumanos que não se enquadrarem apenas entre uma das dimensões de bem e mal. De acordo com os autores esses seres míticos possuem o atributo de encantar e adoecer outros seres - em espacial aos humanos; metamorfoseia-se ou transforma-se em outros seres - de animal a homem e vice-versa e; fazer visagem ou assombrar os homens.

Desse imaginário social engendrou-se a matriz da institucionalização das anciãs nas principais funções da festividade envoltas pelas cerimônias e celebrações as Folias e as Ladainhas e as Danças e Dramatizações até meados da década de 1990 quando essa celebração passa a ser ordenada por grupos mais jovens atrelados à "Disputa dos Botos". Isso implica que na festa do Sairé o Divino é exaltado não por "meninos ou meninas", mas pelas "velhas do Sairé", cujo imaginário social atribui a função de arauto da tradição por serem descendentes das lideranças das "principalezas" Tupinambás que remetiam ao conhecimento da medicina e da magia indígena, das tradições e costumes do lugar e da festa (SMITH, 1879). Na festa do Sairé de Alter do Chão, contemporaneamente, essa característica se expressa emblematicamente, nas cerimônias das Ladainhas e Folias, pela Juíza da festa e a Troneira responsáveis pelos cuidados com a Coroa do Divino e, idiossincraticamente, pela "Saraipora" que aparece na foto $\boldsymbol{a}$ da figura 1, exposta anteriormente, e corresponde à índia mais velha de determinada área e, portanto, detém a confiança de carregar o Semicírculo Sairé, sendo acompanhada pelas "Moças da Fita" que desempenham a função principal de segurar

\footnotetext{
10 Lideranças indígenas femininas que acabam tornando-se ocupando cargo administrativo dos aldeamentos e vilas na Amazônia colonial. A esse respeito ver Rodrigues (1890) e Pereira (1989).
} 
as fitas presas no símbolo do Sairé e, também, “de ajudar a saipora... que como já é velha não dá conta de carregar o Sairé sozinha" (INFORMAÇÃO VERBAL) ${ }^{11}$.

Nas cerimônias das Danças e Dramatizações a relação entre o feminino articulado nas exibições da "Disputa dos Botos" aparece nas expressões da Cabocla Borari que remete às "belas moças da região" (INFORMAÇÃO VERBAL) ${ }^{12}$ que têm um cotidiano atrelado ao uso das águas dos rios locais e convívio com o boto animal e, emblematicamente, pela/na Rainha do Lago Verde, um dos ícones da estrutura ritualística das apresentações no Lago dos Botos e que representa a encantada Iara, protetora das águas. As águas dos corpos hídricos na região correspondem, conforme Maués (1995), a locais onde habitam os encantados ou os seres do fundo, sendo o fundo de rios e bacias hidrográficas importantes espacialidades na cosmologia xamanista ${ }^{13}$, dentre os quais aparece o boto que, como já foi mencionado, exerce um dom dual sobre os humanos de encante e domínio sobre as águas, podendo tanto provocar naufrágios e lavar sujeitos ao "fundo dos rios" como salvá-los de afogamentos, tendo alguns desses aspectos ressaltados nas danças e dramatizações apresentadas no Lago dos Botos. Essa caraterística vinculada aos rios e aos botos põe em evidência a construção do sujeito "Capitão" que aparece na foto $\boldsymbol{b}$ da figura 1, exposta anteriormente, e cuja função na festa do Sairé consiste na autorização e condução das procissões.

Isso porque, o "Capitão" na Amazônia designa mais do que um cargo hierárquico ou uma patente, ele indica certeza e confiabilidade no comando, já que corresponde ao sujeito central na navegabilidade nos rios da bacia amazônica, ele conhece todos os seus bichos, canais navegáveis e pessoas/sujeitos que vivem no local ${ }^{14}$. Conjuntamente, a essa dimensão do "Capitão" articulado a dominialidade dos rios e águas da/na Amazônia ressaltada no interior das cerimônias festivas do Sairé em

\footnotetext{
${ }^{11}$ Informação constatada em relato de entrevista realizada durante trabalho de campo, Alter do Chão, Jan. 2014.

${ }^{12}$ Informação constatada em relato de entrevista realizada durante trabalho de campo, Alter do Chão, Out. 2013.

${ }^{13}$ Segundo Maués (1995, 1999), o xamanismo compreende organização religiosa vinculada a universos compostos pela superposição de indeterminados números de camadas; pela definição de um xamã nascido com o dom ou como ser "encantado" capaz de mediar os mundos visíveis e invisíveis - os bichos do fundo; pela hierarquização dos espíritos conforme seu poder de interação nos dois mundos.

${ }^{14}$ Os instrumentos técnicos possuem mais do que dados geométricos, os homens dos lugares têm uma relação de existência, uma relação afetiva, de medo, de amor, de desamor enfim, uma relação de vida aos sujeitos que conhecem os locais por onde navegam. A esse respeito ver Costa e Góes (2017).
} 
Alter do Chão, enfatiza-se a constituição da figura do "Espanta Cão" que consistia num tocador de violino cujas notas musicais eram responsáveis, por "espantar os maus espíritos" (INFORMAÇÃO VERBAL)" ${ }^{15}$, por “abrir os caminho para que a festa seja abençoada”(INFORMAÇÃO VERBAL) ${ }^{16}$, ou seja, a personagem que assume o papel de "benzedeiro" ou, como designa Maués (1995), de experientes que constituem-se como sujeitos envoltos autorizados para práticas de rezas e expressões corpóreas destinadas a proteção e/ou cura enredadas ao xamanismo.

Nesse sentido, o imaginário social no/do Sairé aparece não como mera abstração do real, mas como tessitura e projeção da 'Bildung' humana que dá base para o real e coerência para o ser (WUNENBURGER, ARAÚJO, 2006). Nas análises documentais, nos trabalhos de campo e entrevistas, constatou-se uma tessitura que projeta Coerência para uma espécie de argumentação cultural da festa do Sairé. Isso porque, assim como Santana (2009, p. 72), se entendeu que essa argumentação é produto de sujeitos culturalmente ativos em que "suas experiências e vivências, suas pequenas e grandes adaptações, suas estratégias de sobrevivência, tornam-nos agentes da inovação e da mudança, transmitindo sua própria argumentação cultural”. Assim compreendida, a argumentação cultural imprime significações a formas espaciais e a suas funções que se formatam, explicita e implicitamente, como intencionalidade de sujeitos e de seus grupos sociais. Essas significações, quando acionadas como bem cultural de enraizamento identitário espacialmente referenciado, tangenciam a categorização de patrimônios que demonstram "as nossas escolhas - o que queremos lembrar e o que não nos importa perder no esquecimento" (PAES, 2010, p. 13). A relação entre passado e presente embutida na categorização de patrimônio e de "ativo de significação" coadunam com a concepção de tradição evidenciada no presente a partir da seleção pela memória de laços e de rupturas com o passado (GRÜNEWALD, 2001).

\footnotetext{
${ }^{15}$ Informação constatada em relato de entrevista realizada durante trabalho de campo, Alter do Chão, Set. 2012.

${ }^{16}$ Informação constatada em relato de entrevista realizada durante trabalho de campo, Alter do Chão, Out. 2013.
} 


\section{A TERRITORIALIDADE FESTIVA DO SAIRÉ COMO PRÁTICA TURÍSTICA EM ALTER DO CHÃO}

Como se demonstrou na seção anterior, a territorialidade festiva do Sairé se configura pela dimensionalidade do vivido territorialmente (RAFFESTIN, 1985, 1993), o que indica que os lugares, como pode ser encontrado em Massey (2008), não são atravessados como pontos ou áreas e o encontro com o outro é mediado por esferas de eventualidades espaço-temporais de coetaneidade (contemporaneidade radical). Assim, a territorialidade festiva do Sairé permite uma analogia com a concepção de cultura assestada por Wagner (1981, 2011) e Sidekum (2003) na qual seu estabelecimento se desenvolve no âmbito de sujeitos concretos cuja margem de manobra à escolha de seus modos operantes incide sobre autodeterminações culturais e/ou sobre processos de endoculturação. A endoculturação delineia-se como processo de especificação cultural à medida que, partindo de Massey (2008), se desenvolve em interações espaciais conectadas à externalidades articuladas a processos internos de um dado lugar. Dentro do movimento turístico essas interações são aceleradas e impelem à necessidade de, cada vez mais, pensar diferenças e singularidades culturais a partir da mobilidade e da conexão socioespaciais, especialmente, quando se pensa o turismo como evento da cultura de contato (SANTANA, 2009) e indutor de subjetivações (GUATTARI, 1992).

De tal modo, a territorialidade festiva como interface de subjetividades coletivas e seu "acontecer" como ator social com projeto de ação em busca de territorializações existenciais. A análise das expressões da/na festa do Sairé revelou que seu imaginário constitutivo induziu à invenção de uma tradição, nos moldes que acena Wagner (1981), que é produto autoconsciente de seus sujeitos sociais, e ainda, como ressalta Santana (2009, p. 72): “a identificação ocorre por meio da enculturação e da sociabilização e, com isso, faz cada um diferente de outros”. Essa invenção de tradição pelos sujeitos locais, pautados em suas memórias coletivas, reintroduziu a festa do Sairé às práticas sociais em Alter do Chão em um período que essa localidade já recebia fluxos turísticos (PEREIRA, 2007), e isso condicionou uma nova densidade ao Sairé, sendo seu "ativo de significação cultural" definidor do sujeito que segundo Sidekum (2003, p. 244) é "uma indeterminação a determina-se no processo cultural". 
Nesses termos, essa nova densidade ao ativo de significação em Alter do Chão a partir da festa do Sairé se evidencia desde 1973 quando de seu recrudescimento local estando, direta ou indiretamente, vinculada ao turismo como um vetor que posicionou (e posiciona) os sujeitos locais diante do mundo e que cria a necessidade de exporem as suas culturas, o que corresponde àquilo que, segundo Urry (1996), como uma imposição das novas formas de existência social a partir da exposição da cultura ou o consumo cultural da cultura que se espraia ao turismo. Na festa do Sairé esse consumo permitiu detectar um ativo de criação de significações em que se pôde observar uma relação entre sociedade e natureza, cujo imaginário é vivenciado pelos sujeitos organizadores da festa como um substrato místico que se conforma por um "Divino” apreciado e expresso por constitutivos subjetivos de sujeitos produtores de tradições na/com o viver amazônico. Assim, a festa do Sairé, que foi objetivada dentro de uma "cultura de contato" pelas vias da religiosidade católica, vivencia novamente o "encontro" com o "outro", dessa vez recortado pelo turismo e por uma nova "cultura de contato" (SANTANA, 2009). Essa criação de tradição como ativos de significações pautaram-se na inserção de "novos" elementos à festa, especialmente em aspectos do passado que se escolheu preservar, fundamentalmente, aqueles articulados na década de 1970 como a procissão fluvial da Busca dos Mastros realizada pela travessia do Lago Verde localizado na área central da vila de Alter do Chão e a como a quase teatralização de algumas danças (ver figura 2 exposta a seguir) como o Cruzador Tupi de influência nordestina e a musicalidade e dança de influência negra como o Lundu e o Marambiré $e^{17}$, essas duas dando visibilidade a existencialização no negro e a inspiração africana remanescente na região quilombola do Pacoval das antigas coroações de reis negros (SANTIAGO, 1996).

Essa esfera de ativos de significações vinculada às danças no Sairé constitui-se no campo festivo de sua territorialidade de maior reelaboração nas últimas décadas fortalecido na década de 1990 pelas políticas públicas brasileiras destinadas a atividade turística, essencialmente, desde o Programa de Desenvolvimento do Ecoturismo na Amazônia Legal - PROECOTUR (PARATUR, 2009). Esse programa foi um marco à consolidação do Polo Turístico do Tapajós no oeste do Pará e consubstanciou políticas posteriores que demarcaram a festa do Sairé como um centro convocador do turismo nesse polo. Inscrevendo definitivamente na festa um elemento simbólico do paradigma

\footnotetext{
17 Informação constatada em notas descritivas das observações dirigidas e nos relatos das entrevistas realizadas nos trabalhos de campo efetuados entre Out. 2013 e Jan. de 2014 em Alter do Chão.
} 
do turismo com um significado simbólico que opera a realidade amazônica na mobilidade turística a partir da introdução/apresentação do espetáculo da "Disputa dos Botos" na festa do Sairé, revisitando performaticamente todo um imaginário de crenças, ritos de pajelanças e lendas que, por não serem católicos, foram, conforme descreve Galvão (1976, p. 8): “degradadas e consideradas como "superstições” das classes economicamente inferiores".

FIGURA 2 - DIMENSÕES DAS EXPRESSÕES DAS DANÇAS NA PRAÇA DA MATRIZ E NA PRAÇA DO SAIRÉ
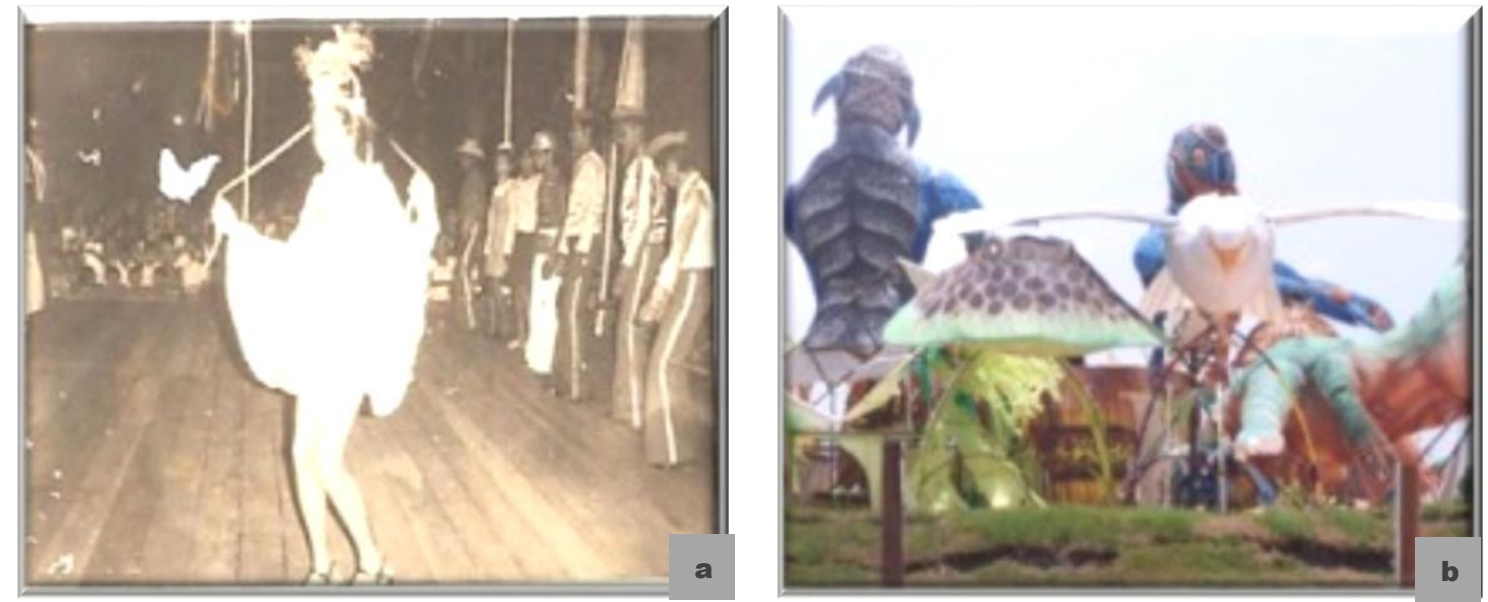

a - Apresentação de dramatização dançante no palanque/palco da Praça da Matriz em 1976; b - Esculturas utilizadas nas apresentações dos Botos e expostas na Praça do Sairé na área do Lago dos Botos.

FONTES: a - extraído de Vasconcelos (2010) disponível em: <www.viconsaga.com.br, acessado em Out. de2015>. e b - CANAL, M. A. F. C., arquivo Pessoal, 2013.

Na figura 2 exposta acima é possível verificar em dois momentos temporais da festa do Sairé de Alter do Chão o construto criativo de apresentações incorporadas ao imaginário amazônico que integra sujeitos sociais a elementos da natureza e reforça aspectos do Divino na Amazônia, o que se verificou pelo uso de grandes esculturas como a pomba branca e a arraia encontradas na foto $\boldsymbol{b}$. Desde 1997 a territorialidade festiva do Sairé tem suas apresentações veiculadas àquilo que, partindo de Mafra (2008), pode-se designar como enunciação espetacular. Essa enunciação no caso do Sairé recebe influência de ressignificações culturais provenientes de outras porções amazônicas inseridas numa teia territorial (RAFFESTIN, 1993) enredada por tessituras do Festival dos Bois em Parintins, Festival das Tribos em Juruti e o Festiara em Belterra (VIA AMAZÔNIA, 2007). Nessa tessitura a festa do Sairé incorpora criativamente a Disputa entre Agremiações Sociocultural Boto Tucuxi e a Associação Boto Cor de Rosa, 
cujas apresentações são realizadas em uma ou duas noites de festa no interior da arena Lago dos Botos dependendo da estrutura organizacional da festa do Sairé em cada ano $^{18}$. Essas apresentações inseriram a festa do Sairé no circuito espacial contemporâneo do "espetacular" e desde 1997 redimensionou o imaginário sobre a lenda do Boto que até então, era secundarizada na territorialidade festiva e, concomitantemente, materializou a ressignificação da festa como atrativo turístico à destinação segmentada em Alter do Chão da qual a festividade do Sairé, também, era secundarizada ${ }^{19}$.

A materialização da festa do Sairé como segmento turístico vinculado à cultura, incisivamente a partir da década de 1990, se inscreve dentro de um movimento mais amplo e fluído de configuração social de encenação e de espetáculo (MENESES, 2006; MAFRA, 2008), em que Urry (1996, p. 131) descreve ser "o modo pelo qual todo tipo de lugar se tornou o centro do espetáculo e da exibição e a nostálgica atração exercida pela "tradição". Isso tudo permite identificar a função do imaginário de criação incessante e indeterminada de formas e imagens como via para expressar alguma coisa (CASTORIADIS, 1991, p. 93), assim como, de instaurar instâncias sociais dentre o que se inscreve o turismo. O turismo enquanto instância mediadora da fluidez sócio espacial, da fuga do cotidiano e do prazer compreende-se por um movimento mais amplo de "ativo de criação de significação" em que o espetáculo turístico precisa ser induzido e indutor pela/da tradição pautada no imaginário social proporcionador de enunciados que, em certa medida, se aproximam da construção imaginativa daquilo que Bachelard (2002, p. 5) chamou de "devaneios materiais que antecedem à contemplação".

Considera-se que as lendas e o pensamento mítico exercem senso explicativo de aspectos essenciais de uma dada realidade da qual emerge como representação social, não sendo, portanto, nem a realidade nem o falseamento desta (BOURDIEU, 2003). Assim, de acordo com Wunenburger e Araújo (2006, p. 16), precisa-se considerar que o valor imaginativo "não reside unicamente nas suas produções, mas também no uso que

\footnotetext{
18 Informação constatada em notas descritivas das observações dirigidas e nos relatos das entrevistas realizadas nos trabalhos de campo efetuados em Ago./Set. de 2012 e entre Out. 2013 e Jan. de 2014 em Alter do Chão.

${ }^{19}$ Informação derivada de relato de organizador da Festa, 38 anos de idade, entrevista realizada em Alter do Chão, Jan. de 2014.
} 
lhes é dado. A imaginação obriga então a formular uma ética, ou mesmo uma sabedoria das imagens". Nessa perspectiva, compreendeu-se que um movimento mais amplo do turismo também tem importância com "ativo de criação de significação" para a festa do Sairé, o que se verificou nas apresentações de danças e dramatizações que a exaltação de elementos indígenas aparece fortemente na elaboração da figura do curandeiro e das pajelanças na Disputa dos Botos enviesada pelo senso explicativo da narrativa mítica do "Boto". Esse senso explicativo narrativo acerca dos botos será arrolado ao campo simbólico festivo do Sairé envolto pelas figuras do boto animal - elemento físico da natureza, que engerado em o boto homem - elemento dimensionador do imaginário amazônico criador, encanta, seduz e conceba o ato sexual com as belas jovens da região.

O uso do mito do "boto" na festa do Sairé pretende, por meio do imaginário social, reforçar as marcas da tradição que irão dar suporte a argumentação cultural local nesse "novo" momento dentro da "cultura de contato" em que, como aponta Santana (2009, p. 14): “esse novo “outro” é, evidentemente, mais próximo e, entretanto, não se torna por isso mais óbvio [...] o sujeito retórico dos estudos, esse "novo indígena" nem sempre se reconhece como membro da tribo (turista)", bem como, em que há uma enorme dificuldade em definir mudanças unilaterais à cultura contemporânea ante seu caráter cada vez mais antiaurática (URRY, 1996) que sob a lógica do o extraordinário, o sensacional, o surpreendente, os prazeres intensos, os devaneios e as fantasias (ARAÚJO, 2001; GRÜNEWALD, 2001) intrínsecos aos signos do turismo. Ainda assim, verificou-se à/pela territorialidade festiva do Sairé o esforço à agregação e a criação de um imaginário que se tangenciou aos marcos teóricos encontrados em Wunenburger e Araújo (2006). De tal modo, mesmo que se tenha identificado uma atenção dispensada à implementação e consolidação da Disputa dos Botos agregadora de esforços sociais locais, principalmente da nova geração e renegadora dos afazeres vinculados às Ladainhas, Folias, Cantos e Danças mais antigas aos senhores e senhoras da localidade, a escolha dessa mitologia como referência à territorialidade festiva do Sairé se apresentou como intensividade de criação existencial de subjetividades locais em alteridade contraposta aos shows de boi bumbá que começavam a ser introduzidos na localidade na metade da década de 1990, e a opção da musicalidade ritmada pelo curimbó - ritmo local que é a junção do carimbó com os tons tribais. 
Isso incorreu em inúmeras outras inventividades culturais locais como o resgate da escrita Çairé em contraposição a Sairé e o fortalecimento de grupos folclóricos e as danças tradicionais que serão inseridas ao contexto das encenações realizadas no Lago dos Botos durante as disputas. Dessa forma, a festa do Sairé revelou-se como relevante nas estratégias de mobilização cultural vinculadas ao turismo, essencialmente na fugacidade dos prazeres intensos (DURKHEIM, 1989), já que, como escreve DaMatta (1983, p. 45), as festas populares engendram "momentos especiais de convivência social [...] momentos extraordinários marcados pela alegria", em que o "ir-ao-encontro-dooutro" e se inserir a "numa coletividade" são exacerbados, principalmente quando se trata das danças (MAIA, 1999). O “ir-ao-encontro-do-outro", em uma sociedade desprendida dos constrangimentos impostos pela "alta cultura" e permeada pelo “princípio do prazer”, assume expressividade e caráter de evento empresarial. Esses indicativos marcam a reelaboração da festa do Sairé em Alter do Chão, colocando-a no circuito oficial do turismo brasileiro e dando projeção a um novo fazer dentro da festa a disputa dos Botos, bem como a um novo espaço - O lago dos Botos.

A formatação dos festivais nos moldes de evento empresarial, na visão de Amaral (1998), de Maia (1999) e de Mafra (2008), não implica necessariamente numa desmobilização das mediações humanas, essencialmente, quando se assinala o entrelace entre o imaginário individual e o imaginário social. Desse entrelaçamento, na perspectiva de Wunenburger e Araújo (2006, p. 73), engendra-se um diálogo com "as ressonâncias cósmicas, psíquica e poética da vida", o que parece claro quando da escolha do referencial dos Botos, dado o seu papel simbólico religioso e profano (o auxiliador e símbolo da eucaristia - o Tucuxi, e o atrapalhador e sexual - o Cor de Rosa, e ainda o festivo e "emprenhador" - o boto Homem). A exposição desse duplo movimento, intrínseco à lógica do local do Sairé, solidariza-se com as teses de Araújo (2001) e Santana (2009) sobre o indicativo de "episódios de revitalização", originários da/na prática do turismo e cujos substratos podem (também) variar da adaptação e/ou recuperação de tradições até aos processos de construção de identidades coletivas, os quais não somem nem das áreas visitadas nem dos centros de emissão de turistas. Isso porque, ao se considerar a atividade turística como uma atividade/processo substrato da cultura de contato ou cultura do encontro, precisa-se entender que necessariamente haverá empréstimos e adaptações cuja interação é única. 
Isso evidencia um espaço de esfera de coetaneidade, onde a reconstrução dos sujeitos e seus patrimônios no/pelo turismo e sua relação de "contato" ou de "encontro" afeta também o turista e seu retorno ao cotidiano (SANTANA, 2009). O que indica, em longo prazo, uma tendência à incorporação da cultura de contato também nos lugares de origem dos turistas. Tendência essa que pode ser maior ou menor quando menos "padronizado" for o encontro turístico entre as culturas. Ou ainda, como disserta Guattari (1992, p. 18-19): “a constituição de complexos de subjetivação [...] o conjunto das condições que torna possível que instâncias individuais e/ou coletivas estejam em posição de emergir como território existencial auto-referencial". Esse conjunto de condições também é apreciado por Sidekum (2003, p. 244) como necessário à autodeterminação do sujeito em "processos de endoculturação". Tal constatação coloca um (e aqui cita-se apenas um dos) paradoxo na cultura de contato vinculada pelo turismo, qual seja: a de ordem e desordem do movimento. Se, por um lado, para se efetivar o turismo não se pode prescindir ao ordenamento espacial e, concomitantemente, a padrões de uso territorial, por outro lado, ele precisa deixar "pontos frouxos" (GUATTARI, 1992) nesse território que provoque aparentemente desordem, mas que intrinsecamente se correlacione ao efetivo "encontro" embutido, teórica e empiricamente, nas culturas de contato. Pois, como assesta Massey (2008, p. 175), não se viaja "através do espaço", já que esse é produto de relações sociais em que sujeitos e elos são constantemente recriados.

Compreendida dessa forma, a relação social turística indica o turista também como sujeito ativo que reconstrói, produz ou mantém tanto a sua cultura como a do visitado, ainda mais se, como Sidekum (2003, p. 295), visualiza-se a cultura como campo fronteiriço em que "o outro está dentro e não fora do nosso contexto cultural”, portanto, como campo contínuo de experiências inovadoras e transitórias onde a produção de especificidade deriva também de "interações com que está além" (MASSEY, 2008, p. 105), de conexões descontinuamente especializadas. Mas o turista só usa e consome parcialmente a cultura, e não poderia ser diferente quando se entende a cultura como construto de vivências e de densidades aprendidas pela lógica dos lugares em que são vivificadas e cuja totalidade só aí pode ser reconhecida (SANTOS, 1999). Dessa forma, o turista e o turismo, ao buscarem as cotidianidades culturais a serem usadas, colocam os sujeitos dos lugares visitados no movimento de "conversão ao 
turismo". Assim, quando se anuncia "o espetáculo do pôr do sol em Alter do Chão" ou ainda "um show folclórico, temperado com canto Amazônico e bailados nativos" (VIA AMAZÔNIA, 2007), cria-se uma imagem de Alter do Chão pautada em "cotidianidades espetaculares". Como alerta Mafra (2008, p. 68), se deve entender e analisar o espetáculo como arena de mobilização social e de processo declarativo nas diversas escalas geográficas, e ratifica o autor: "vivenciamos os tempos do espetáculo, e não há como dele fugir".

Nessa perspectiva, como acena Santiago (1996) e reforça Mafra, é preciso analisar os momentos e as possibilidades em que os sujeitos do espetáculo definem autonomias que se entrecruzem nas esferas do sensacional, do surpreendente, do extraordinário, da constituição de personagens e narrativas, da dramaturgia. E, dessa forma, pensar o imaginário e o imaginativo "como explicação implicativa do real vivido e não como mera explicação abstrata do real” (WUNENBURGER; ARAÚJO, 2006, p. 51). Essa caraterística de real vivido emprestada ao imaginário também prevalece na visão de Meneses (2006, p. 23) sobre o patrimônio histórico-cultural e seu valor turístico, os quais remetem à "construção/invenção do passado como atrativo para quem viaja”. Para o autor, o patrimônio histórico-cultural deve ser pensado em sua dinâmica de ter e de devir, pois está imerso em cotidianidades de grupos sociais historicamente em movimento e em constituição de seus próprios tempos, esses mesmos tendo o patrimônio como um referencial de subjetivação, já que, de acordo com Sidekum (2003, p. 243): "a subjetividade e a cultura são correlações inseparáveis". Tentando uma aproximação dessa proposição sobre o patrimônio cultural com a proposta de Guattari (1992) sobre as "instâncias locais de subjetivação coletiva", se pode pensar o patrimônio cultural e, portanto as festas como mediadoras da recomposição de "uma corporeidade existencial, de sair de seus impasses repetitivos e, de alguma forma, de se re-singularizar". Nesse sentido, encontra-se um campo para questionar e pesquisar a partir das festas, do turismo, da cultura e de seus complexos de subjetivações. 


\section{CONSIDERAÇÕES FINAIS}

A festa do Sairé demonstrou-se um fazer festivo que atrela aspectos do imaginário amazônico como a água, as relações como os encantados e visagens como o Boto e expressões das celebrações do Espírito Santo enredadas ao cristianismo. A partir dessas relações e expressões observou-se uma intrínseca produção de subjetividades coletivas e a objetivação de projetos que mediam o fazer o Sairé como territorialidade festiva. No que tange à festa do Sairé o imaginário amazônico define uma criação distintiva do Divino em que sua territorialidade festiva do Sairé apareceu como referência ao patrimônio cultural dos sujeitos que a organizam em Alter do Chão, fundamentalmente, no que diz respeito ao fazer a festa e a seus sistemas de relações que criam subjetividades individuais e coletivas das quais derivam sentidos a projetos e engajamento a ações sociais e objetivação de mundo.

De tal modo, a festa do Sairé e sua relação com o imaginário amazônico apresentam materialidade e imaterialidade que indicam coesão social aos grupos que organizam o fazer festivo e a expressão cultural diferenciada sobre/com o Divino, sendo isso, vivenciado como um mecanismo de autoafirmação construído em/como "episódios de revitalização" no interior de uma prática do turismo permite pensar em processos e tendências de efetivação do patrimônio cultural que não se especifica apenas em seus processos internos e isolamento espacial, mas em articulações conexas com o mundo. E, nesse caso, os laços e rupturas com o passado evidenciam sua autenticidade histórica, seja nas práticas festivas enredadas pelas expressões das ladainhas e folias, seja nas articuladas mitológicas de suas danças, já que inseridas num quadro conjuntural e não meramente em uma estrutura passiva e inerte, o que demonstrou que esse fazer festivo não se restringe apenas a um evento ou um calendário turístico. Ante o uso turístico da cultura, constatou-se que o imaginário social que operou na realidade e a racionalidade no campo social da festa do Sairé enunciaram uma territorialidade cuja autoafirmação dos organizadores da festa enquanto subjetividade coletiva e ação social implicavam no delineamento do próprio Sairé no imaginário amazônico. 


\section{REFERÊNCIAS}

AMARAL, R. de C. de M. P. Festa à brasileira: significados do festejar, no país que "não é série". Tese de Doutorado. São Paulo: Departamento de Antropologia, FFLCH, USP, 1998.

ARAÚJO, S. M. de. Artifício e Autenticidade: o turismo como experiência antropológica. In: BANDUCCI Jr, Á.; BARRETTO, M. (Orgs.). Turismo e identidade local: uma visão antropológica. Campinas: Papirus, 2001.

BATES, H. W. O naturalista do rio Amazonas. São Paulo: Companhia Editora Nacional, 1962.

BACHELARD, G. A água e os sonhos. Ensaios sobre a imaginação da matéria. São Paulo: Martins Fontes, 2002.

BERTONCELLO, R. Turismo y Patrimônio: entre la cultura e el negocio. In: PAES, M. T. D.; OLIVEIRA, M. R. da S. Geografia, turismo e patrimônio cultural. São Paulo: Annablume, 2010.

BOURDIEU, P. O Poder simbólico. 6. ed. Rio de Janeiro: Bertrand, 2003.

CASCUDO, L. da C. Dicionário do Folclore Brasileiro. 6. ed. São Paulo: Editora da USP, 1988.

CASTORIADIS, C. A instituição imaginária da sociedade. São Paulo, Rio de Janeiro: Paz e Terra, 1991.

COSTA, M. A. F. Turismo e patrimônio cultural: a Festa do Sairé em tempos de mudança cultural. In: CARVALHO, L. G.; MILEO, B. P. (Orgs.). Patrimônio cultural e direitos culturais na Amazônia: experiências de pesquisa e gestão. Santarém/PA: UFOPA, 2012.

; GÓES, E. M. Territorialidade festiva e idioma do sagrado na Amazônia: o Divino na Festa do Sairé de Alter do Chão- Pará. In: LEAL, A. C.; BORDALO, C. A. L.; NUNES, J. O. (Orgs.). A geografia do Pará em múltiplas perspectivas: natureza, urbano, rural e cultura. Tupã: ANAP, 2017.

DAMATTA, R. Carnavais, malandros e heróis. 4. ed. Rio de Janeiro: Zahar, 1983.

DEMATTEIS, G.; FERLAINO, F. Il mondo e i luoghi: geografie delle identità e del cambiamento. Torino: IRES, 2003.

DURKHEIM. E. As formas elementares da vida religiosa. São Paulo: Paulista, 1989.

FERREIRA, E. O berço do Çairé. Santarém: Edição do Autor, Editora Valer, 2008.

GALVÃO, E. Santos e visagens. São Paulo: Ed. Nacional/INL, 1976.

Turismo \& Sociedade (ISSN: 1983-5442). Curitiba, v. 11, n. 2, p. 192-216, maio-agosto de 2018. 
GRÜNEWALD, R. de A. Turismo e o "resgate" da cultura Pataxó. In: BANDUCCI Jr, Á.; BARRETTO, M. (Orgs.). Turismo e identidade local: uma visão antropológica. Campinas: Papirus, 2001.

GUATTARI, F. Caosmose: um novo paradigma estético. Rio de Janeiro: Editora 34, 1992.

LAKATOS, E. M.; MARCONI, M. de A. Fundamentos de metodologia científica. São Paulo: Atlas, 1993.

LUStOSA, D. A. A. Dom Macedo Costa de Almeida: Bispo do Pará. Belém: SECULT, 1992.

MAFRA, R. Entre o espetáculo, a festa e a argumentação - mídia, comunicação estratégica e mobilização social. Belo Horizonte: Autêntica, 2008.

MAIA, C. E. S. Ensaio interpretativo da dimensão espacial das festas populares. Proposições sobre festas brasileiras. In: ROSENDAHL, Z.; CORRÊA, R. L. (Orgs.). Manifestações da cultura no espaço. Rio de Janeiro: EdUERJ, 1999.

MASSEY, D. Pelo espaço: uma nova politica da espacialidade. Rio de Janeiro: Bertrand, 2008.

MAUÉS, R. H. Padres, pajés, santos e festas: catolicismo popular e controle eclesiástico. Um estudo antropológico numa área do interior da Amazônia. Belém: CEJUP, 1995.

MENESES, J. N. C. História e turismo cultural. Belo Horizonte: Autêntica, 2006.

NITSCHE, L. B.; BAHL, M. Contribuições de base geográfica cultural para o estudo do turismo em comunidades locais. Turismo e Sociedade. Curitiba, v. 9, n. 2, p. 1-18, 2016.

PARATUR. Companhia Paraense de Turismo. Diagnóstico da área e das atividades turísticas do Polo Tapajós - PA. Belém: PARATUR/Ministério do Turismo, 2009.

PEREIRA, N. O Sairé e o Marabaixo: tradições da Amazônia. Recife: FUNDAJ, Editora Massangana, 1989.

PEREIRA, L. N. Morfologia urbana e atrativa de destinações turísticas: a importância da imagem na compreensão do sistema turístico da vila de Alter do Chão (Santarém-Pa). Dissertação de mestrado. Mestrado em Turismo e Hotelaria. Balneário Camboriú-Santa Catariana: CE/UVI, 2007. 
PAES, M. T. D.; OLIVEIRA, M. R. da S. Geografia, turismo e patrimônio cultural. São Paulo: Annablume, 2010.

PRATS, L. El concepto de patrimônio cultural. Política y Sociedad, 1998, v. 27, p. 6376. Extraído de: 〈www.antropologiasocial.org〉. Consultado em: out. 2014.

RAFFESTIN. C. Territorializzazione, deterritorializzazione, riterritorializzazione e informazione. In: TURCO, A. (Org.). Regione e regionalizzazione. Milano: Angeli, 1985.

Por uma geografia do Poder. São Paulo: Ática, 1993.

RODRIGUES, J. B. Poranduba amazonense, ou kochiyma-uara porandub, 18721887. Rio de Janeiro: Typ. de G. Leuzinger \& Filhos, 1890.

SANTANA, A. Antropologia do Turismo: analogias, encontros e relações. São Paulo: Alep, 2009.

SANTOS, M. A natureza do espaço: espaço e tempo; razão e emoção. 3. ed. São Paulo: HUCITEC, 1999.

SANTIAGO, M. do S. F. Pelos caminhos do Sairé - um estudo do aproveitamento da cultura popular no Teatro - Educação. Tese de Doutorado. Doutorado em Artes Cênicas. São Paulo: ECA/USP, 1996.

SIDEKUM, A. Alteridade e interculturalidade. In: (Org.) Alteridade e multiculturalismo. Ijuí/Rio Grande do Sul: Editora Unijuí, 2003.

SMITH, H. Brazil, the Amazons and the coast. New York: Charles Scribner's Sons, 1879.

URRY, J. O olhar do turista: lazer e viagem nas sociedades contemporâneas. São Paulo: Studio Nobel/SESC, 1996.

VASCONCELOS, M. L. L. de (Coord.) Diagnóstico sócio-ambiental de Alter do Chão- Relatório Projeto Agenda Cidadã. Santarém: Escola Indígena BORARI/SEMED-PMS/UFPA, 2010. Extraído de: 〈www.viconsaga.com.br>. Visitado em: out. 2015.

VEJA. São Paulo: Abril, 1968-, n. 33, 17 ago. 2011.

VIA AMAZÔNIA. Santarém - PA: Via Amazônia produções, 2003-, n. 21, set. 2007.

WAGNER, R. The Invention of Culture. Chicago: The University of Chicago Press, 1981. 
O apache era o meu reverso. Revista de Antropologia, São Paulo, USP, v. 54, n. 2, 2011, p. 956-978.

WUNENBURGER, J.; ARAÚJO, A. F. Educação e imaginário: introdução a uma filosofia do imaginário educacional. São Paulo: Cortez, 2006.

Recebido em: 18-09-2018.

Aprovado em: 18-08-2018.

Versão finalizada para publicação: 28-12-2018. 